\title{
Kesehatan dan Pembangunan Sumber Daya Manusia
}

\author{
Soekidjo Notoatmodjo*
}

\begin{abstract}
Abstrak
Sebagai aset utama pembangunan bangsa, sumber daya manusia selalu dijadikan tolak ukur keberhasilan kualitas pembangunan suatu bangsa. Indonesia berada di urutan 111 dari 176 negara-negara di dunia, atau urutan ke 6 dari 10 negara-negara Asia Tenggara (Asean). Artikel ini bertujuan untuk membahas berbagai aspek ketertinggalan bangsa Indonesia di bidang kesehatan serta upaya untuk memperbaikinya. Metoda yang digunakan adalah kajian yang rasional melaui tinjauan pustaka dan pemikiran yang logis. Untuk mengejar ketinggalan di bidang kesehatan perlu dilakukan perubahan pradigma dari "health for survival" yang berorientasi pada orang sakit dan mengutamakan kuratif dan rehabilitatif kepada "heath for human development" yang mengutamakan orang sehat yang berorientasi pada promotif dan preventif. Aset utama bangsa meliputi sumber daya alam (SDA) dan sumber daya manusia (SDM). Namun, sumberdaya manusia berperan lebih menentukan karena peranannya dalam mengelola sumber daya alam. Dalam pembangunan bangsa aspek kualitas lebih penting daripada kuantitas yang telah menempatkan bangsa Indonesia peringkat keempat terbesar di dunia, setelah India, Cina dan Amerika Serikat. Urutan Indonesia yang jauh di bawah Singapura, Jepang dan Korea membuktikan bahwa kualitas sumber daya manusia Indonesia masih rendah.
\end{abstract}

Kata kunci : Kesehatan, pembangunan, sumber daya manusia.

\section{Abstract}

As the main asset of national development, human resource is always used as success indicator of quality development in the country. Indonesia ranked in position 111 out of 176 countries in the world, ranked number 6 out of 10 Southeast Asian (ASEAN) countries. This article aimed at discussing aspects relating to the slow and under development of health sector and efforts to accelerate it. Method used is rational review through literature review and logical thinking. To catch up health sector under development, there is a need for paradigm change from "health for survival" which is oriented toward sick people and prioritizing curative and rehabilitative approaches to "health for human development" which is oriented toward healthy people and prioritizing promotive and preventive approaches. Main assets of a nation include natural resources and human resources, however, human resources is deemed more important due to its role to manage the natural resources. In national development, quality is more important than quantity. Quantitatively, Indonesia ranked fourth after India, China, and USA as the most populated countries, but in term of rank of development index, Indonesia is positioned far below Singapore, Japan, and Korea which are less populated an inarguable evidence of low quality of Indonesia's human resources.

Key words : Health, development, human resources. 
Akhir abad ke-20 ditandai oleh pergeseran paradigma pembangunan dari pembangunan ekonomi ke paradigma pembangunan sumber daya manusia. Pada paradigma pembangunan lama, ekonomi menjadi panglima yang menilai keberhasilan pembangunan dari aspek perkembangan ekonomi yang diukur dari peningkatan pendapatan per kapita. Kelemahan pembangunan dengan parameter ekonomi dengan indikator pendapatan per kapita adalah tidak mencerminkan pemerataan dan keadilan. Pendapatan per kapita yang tinggi tidak menjamin pemerataan dan keadilan bagi seluruh warga bangsa. Paradigma ekonomi tersebut diganti oleh oleh Program Pembangunan PBB (United Nation Development Programes) menjadi paradigma pembangunan sumber daya manusia yang tidak hanya mengukur keberhasilan pembangunan dari income per kapita tetapi juga menggunakan indeks kualitas sumber daya manusia (Human Development Index) (HDI).

Indeks HDI tersebut ditentukan oleh 3 komponen utama yang meliputi pendidikan, kesehatan, dan ekonomi. Pendidikan diukur dari rata-rata tingkat pendidikan penduduk, kesehatan diukur antara lain dari angka harapan hidup, kematian bayi, kematian ibu. Sementara perkembangan ekonomi diukur dari indikator income per kapita. Dengan indikator HDI, pada tahun 2002 UNDP menempatkan Indonesia di peringkat 111 dari 177 negara anggota PBB dan diperingkat ke 6 dari 10 anggota Asean. ${ }^{1}$

Di bidang kesehatan, angka harapan hidup ratarata waktu lahir bangsa Indonesia sudah mencapai 66,6 tahun, tetapi masih jauh dibawah Singapura yang tertinggi di Asean (78,0 tahun). Di bidang pendidikan, angka melek huruf orang dewasa $(87,9 \%)$ masih jauh dibawah Brunei Darusalam $(93,9 \%)$. Sedangkan, untuk indikator angka penduduk yang memasuki sekolah (attendance school rate) (65\%) jauh lebih kecil daripada Singapura $(87 \%)$. Di bidang ekonomi, produk domestik kasar (gross domes- tic product atau GDP) (US\$ 3.230 per tahun) jauh dibawah Singapura (US\$ 24.040 per tahun). (Lihat Tabel 1)

Dalam rangka pembangunan bangsa dengan paradigma pembangunan baru, tiga sektor tersebut (pendidikan, kesehatan, dan ekonomi) harus memperoleh perhatian pemerintah secara seimbang. Untuk meningkatkan sumber daya manusia melalui sektor pendidikan, pemerintah telah mengeluarkan kebijakan yang dituangkan dalam UU, yakni dengan mengalokasikan anggaran pendidikan sebesar $20 \%$ dari anggaran belanja negara, meskipun demikian realisasi kebijakan ini masih jauh dari yang diharapkan.

Selanjutnya, untuk meningkatkan peran sektor kesehatan dalam pembangunan bangsa perlu diupayakan peningkatan kualitas pelayanan kesehatan terutama pelayanan preventif dan promotif, tanpa meninggalkan pelayanan kuratif dan rehabilitatif. Di samping itu, pendidikan tenaga kesehatan berperan sangat besar dalam upaya peningkatan kualitas SDM, mengingat pendidikan tenaga kesehatan berdampak ganda terhadap upaya peningkatan kualitas sumber daya manusia.

Di satu pihak, pendidikan dapat menghasilkan tenaga yang mampu meningkatkan kualitas pelayanan kesehatan yang pada akhirnya berdampak pada meningkatnya kualitas SDM. Di lain pihak, pendidikan tenaga kesehatan merupakan bagian upaya mencerdaskan bangsa yang pada gilirannya berdampak pada peningkatan kualitas SDM.

Peran lembaga pendidikan meningkatkan SDM bangsa Indonesia, khususnya di bidang kesehatan dapat dilihat dari laporan Departemen Kesehatan. Hingga akhir tahun 2003, telah terselenggara pendidikan tenaga kesehatan oleh 180 institusi pendidikan yang tergabung dalam Politeknik kesehatan, dan oleh 683 institusi pendidikan tenaga kesehatan di luar kelembagaan politeknik kesehatan menengah,

Tabel 1. Rangking Indeks Pembangunan Manusia

\begin{tabular}{clcccc}
\hline HDI Rank & Countries & Life Expectancy & Literacy Rate & School Attendace & Annual GDP(US\$) \\
\hline 3 & Australia & 79,1 &.. & 99 & 28.260 \\
9 & Japan & 81,5 &. & 84 & 26,940 \\
25 & Singapura & 78,0 & 92,5 & 87 & 24.040 \\
33 & Brunei & 76,2 & 93,9 & 73 & 9.210 \\
59 & Malysia & 73,0 & 88,7 & 70 & 7.120 \\
76 & Thailand & 69,1 & 92,6 & 73 & 4.170 \\
83 & Philippines & 69,8 & 92,6 & 81 & 3.230 \\
111 & Indonesia & 66,6 & 87,9 & 65 & \\
\hline
\end{tabular}

Sumber :

UNDP, Human Development Report 2004, dalam Indonesia Health Profile 2005 
Tabel 2. Jumlah Institusi Pendidikan Tenaga Kesehatan di Indonesia, 2003

\begin{tabular}{lccc}
\hline Institusi Pendidikan & Pemerintah & Swasta & Jumlah \\
\hline Keperawatan & 385 & 666 & 1.051 \\
Farmasi & 114 & 132 & 246 \\
Kesehatan masy/Kesling & 12 & 38 & 50 \\
Gizi & 26 & 18 & 44 \\
Fisio therapy & 3 & 32 & 35 \\
Teknik /electro medik & 30 & 126 & 156 \\
Faklutas Kedokteran & 23 & 23 & 45 \\
Fak. Kesmas/Stikes & 9 & 31 & 40 \\
\hline
\end{tabular}

Sumber: Profil Kesehatan, 2003

akademi atau Diploma III. Di samping itu, tenaga kesehatan professional tingkat sarjana dihasilkan oleh berbagai perguruan tinggi negeri dan sawasta meliputi Fakultas Kedokteran, Fakultas Kedokteran Gigi, Fakulatas atau Sekolah Tinggi Kesehatan Masyarakat, Fakultas Keperawatan dan Farmasi. ${ }^{2}$ (Lihat Tabel 2)

\section{Paradigma Baru Pelayanan Kesehatan}

Kesehatan bukanlah kondisi yang "statis", dia juga bukan sesuatu yang bersifat dikotomi sehat dan sakit, tetapi dia bersifat dinamis, progesif dan kontinum. Hal ini telah disadari oleh WHO, terbukti dengan perumusan kembali kesehatan pada tahun 1988. Selanjutnya, rumusan WHO tersebut diangkat dalam UU Kesehatan RI No. 23/1992. Kesehatan atau sehat adalah keadaan sejahtera dari badan, jiwa, dan sosial yang memungkinkan setiap orang hidup produktif baik secara ekonomi maupun sosial. Ini berarti bahwa kesehatan tidak hanya mempunyai dimensi fisik, mental, dan sosial saja, tetapi juga mencakup dimensi ekonomi. Dengan demikian, seseorang secara fisik, mental dan sosial dinyatakan sehat, tetapi tidak produktif secara ekonomi atau sosial, orang tersebut tidak dapat dinyatakan sehat. Secara ekonomi, produktivitas diukur dari pekerjaan, secara sosial diukur dari berbagai kegiatan yang berhubungan dengan peningkatan kualitas hidup diri, orang lain ataupun masyarakat. Dengan demikian, agar pelayanan kesehatan relevan dengan peningkatan derajat kesehatan bangsa, diperlukan berbagai kebijakan pelayanan kesehatan baru. Dengan demikian, paradigma pelayanan kesehatan harus diubah dari pelayanan kesehatan yang konvensional ke pelayanan kesehatan paradigma baru.

Karakteristik pelayanan kesehatan konvensional meliputi: (a) Sehat dan sakit dipandang sebagai dikotomi seperti "hitam" dan "putih". (b) Pelayanan kesehatan dimaknai sebagai pengobatan dan penyembuhan. (c) Pelayanan kesehatan diidentikkan dengan Rumah Sakit dan Poli Klinik. (d) Tujuan pelayanan kesehatan adalah meringankan penderitaan dan mencegah atau menunda komplikasi dan kematian. (e) Tenaga pelayanan kesehatan yang utama adalah dokter. (f) Sasaran pelayanan kesehatan adalah individu yang sakit.

Berbagai program pelayanan kesehatan yang ditujukan untuk kelangsungan (Health Programs for Survival) tersebut harus diubah ke Pelayanan Kesehatan Paradigma Baru, dengan karakteristik: (a) Sehat dan sakit bukan sesuatu yang dikotomi, sehat bukan berarti tidak sakit, dan sakit tidak berarti tidak sehat. (b) Pelayanan kesehatan tidak hanya berfungsi menyembuhkan dan memulihkan, tetapi mencakup preventif dan promotif. (c) Pelayanan kesehatan bukan hanya Rumah Sakit dan Poliklinik. (d) Tujuan pelayanan kesehatan yang utama adalah peningkatan kesehatan (promotif), dan pencegahan penyakit (preventif). (e) Tenaga pelayanan kesehatan yang utama adalah kesehatan masyarakat. (f) Sasaran utama pelayanan adalah kelompok atau masyarakat yang sehat. Pergeseran paradigma pelayanan kesehatan ini akan mengantarkan berbagai program kesehatan pada pengembangan sumber daya manusia (Health Programs for Human Development).

\section{Kesehatan dan Hak Azasi Manusia}

Pembangunan bangsa pada dasarnya bertujuan memenuhi hak-hak azasi warga negara mencapai kesejahteraan, termasuk hak azasi kesehatan. Deklarasi Hak Azasi Manusia PBB menyatakan: "Everyone has right to standard of living adequate for health and well being of himself and his family, including food, clothing, housing and medical care". Deklarasi ini jelas menyebutkan bahwa setiap warga mempunyai hak yang sama dalam memperoleh standar hidup yang layak untuk kesehatan, minimal meliputi makanan dan minuman, pakaian, dan tempat tinggal atau "pangan", "sandang" dan "papan". Lebih lanjut, deklarasi tersebut dipertegas dalam Konstitusi WHO tahun 1946 tentang hak azasi kesehatan bagi setiap orang atau warga bangsa. "Setiap orang mempunyai hak atas informasi kesehatan, privasi, menikmati teknologi kesehatan, ketersediaan makanan dan gizi, mencapai jaminan standar hidup optimal dan jaminan sosial". Di Indonesia, hak azasi dan kesehatan juga telah dirumuskan dalam UUD 45 setelah Amandemen. (a) Setiap orang berhak hidup sejahtera lahir dan batin, bertempat tinggal dan mendapat lingkungan hidup yang baik dan sehat serta memperoleh pelayanan kesehatan. (b) Negara bertanggung jawab atas penyediaan fasilitas pelayanan kesehatan dan fasilitas pelayanan umum yang layak. ${ }^{3}$

Hak azasi dan pelayanan kesehatan, juga telah dirumuskan dalam Deklarasi Alma Ata tahun 1978, tentang Primary Health Care, yang telah disepakati 
untuk dilaksanakan oleh negara-negara yang ikut menandatanganinya termasuk Indonesia. Departemen Kesehatan mengembangkan PKMD (Pembangunan Kesehatan Masyarakat Desa) yang konsep dan implementasi di Indonesia sudah ada sebelum tahun 1978 di Banjarnegara, Jawa Tengah. Secara singkat, kegiatan-kegiatan Pelayanan Kesehatan Primer mencakup pelayanan kesehatan langsung dan secara tidak langsung atau prakondisi kesehatan, meliputi (a) Perawatan Kesehatan: (perawatan KIA dan KB, imunisasi, pelayanan penyakit dan kecelakaan, penyediaan obat-obatan pokok). (b) Pra kondisi untuk kesehatan: (pendidikan untuk mengatasi masalah kesehatan; promosi penyediaan makanan dan nutrisi yang tepat; penyediaan air bersih dan sanitasi lingkungan).

\section{Kesehatan dan Tujuan Pembangunan Milinium}

Kesepakatan global yang terdiri dari 189 negara termasuk Indonesia bertekad untuk menghapuskan kemiskinan, keterbelakangan dan ketertinggalan di dunia dalam era milinium. Kesepakatan global ini merumuskan target-target yang akan dicapai sampai dengan tahun 2015, yang dirumuskan dalam 8 "Tujuan Pembangunan Milinium" atau "Millennium Development Goals" yang meliputi (a) Pemberantasan kemiskinan dan kelaparan. (b) Mencapai pendidikan dasar untuk semua. (c) Mendorong kesetaraan gender dan pemberdayaan perempuan. (d) Menurunkan angka kematian anak. (e) Meningkatkan kesehatan ibu. (f) Memerangi HIV/AIDS, malaria, dan penyakit menular lainnya. (g) Menjamin keberlanjutan hidup. (h) Mengembangkan kemitraan global untuk pembangunan. ${ }^{4}$

Sasaran akhir delapan tujuan pembangunan milinium tersebut adalah pengembangan kualitas sumber daya manusia. Kedelapan sasaran pembangunan milinium tersebut merupakan sasaran antara pembangunan kualitas sumber daya manusia. Selanjutnya dari target-target dalam rangka mewujudkan kualitas SDM tersebut, empat target antara lain adalah berkaitan dengan sektor kesehatan.

Uraian tersebut di atas menjelaskan peran kesehatan yang penting dalam pembangunan kualitas sumber daya manusia sebagai aset utama pembangunan bangsa. Selanjutnya, kualitas SDM ditentukan oleh dua faktor yakni fisik dan non fisik, terutama intelektual. Kualitas fisik dan kualitas non fisik yang diukur dari status gizi dan IQ atau tingkat kecerdasan ditentukan oleh gizi makanan. Makanan bergizi lengkap sebagai salah satu aspek kesehatan, sangat menentukan perkembangan fisik dan intelektual yang menentukan kualitas sumber daya manusia. Oleh sebab itu, kecukupan gizi secara kuantitatif dan kualitatif sangat menentukan kualitas sumber daya manusia.
Kecukupan makanan bergizi bagi pengembangan kualitas SDM diperlukan sejak dalam kandungan. Selain itu, lingkungan fisik maupun, sosio-budaya dan ekonomi juga harus berperan kondusif mendukung kesehatan. Dengan demikian, tidak berlebihan jika dinyatakan bahwa "kesehatan merupakan pengawal pertumbuhan generasi muda”.

Kesehatan adalah merupakan potensi dasar dan alami dari setiap individu yang sangat diperlukan pada awal kehidupan dan pertumbuhan manusia. Apabila seorang anak lahir dan berkembang dalam kondisi yang tak terpenuhinya unsur dasar tersebut akan menghambat pertumbuhan dan atau perkembangan fisik dan mental. Hal ini berarti mutu sumber daya manusia tersebut rendah. Dengan perkataam lain seseorang yang sejak di dalam kandungan sampai usia pertumbuhan dan perkembangannya dalam kondisi dan lingkungan yang tidak sehat, maka hasilnya kualitas SDM tersebut juga rendah. ${ }^{1}$

Mengingat pentingnya posisi pembangunan kesehatan dalam pembangunan SDM suatu bangsa seperti yang telah dirumuskan dalam MDG's, maka pembangunan kesehatan harus diarahkan untuk pembangunan sumber daya manusia yang berkualitas. Berbicara indikator kesehatan dari perspektif "paradigma sehat" dewasa ini, seyogyanya menggunakan indikator positif, bukan indikator negatif seperti yang selama ini digunakan. Indikator kesehatan harus digeser dari indikator negatif (angka kematian, angka kesakitan, dan sebagainya) ke indikator positif. Indikator-indikator kesehatan positif antara lain: kelainan patofisiologis, kemampuan fisik, misal: aerobik, ketahanan dan kelenturan sesuai umur, kebugaran, penilaian atas kesehatan sendiri, Indeks Masa Tubuh (IMT), yang dihitung dengan rumus:

$$
\text { IMT }=\frac{\text { Berat Badan (dalam Kg) }}{\text { Tinggi Badan (dalam meter) kwadrat }}
$$

Keterangan : $\begin{array}{ll}<18 & =\text { Kurus } \\ 18-24 & =\text { Normal } \\ 25-33 & =\text { Gemuk } \\ >33 & =\text { Obesitas }\end{array}$

Dari uraian-uraian tersebut di atas dapat disimpulkan bahwa peran kesehatan dalam pembangunan bangsa meliputi; (1) Membangun generasi yang akan datang menjadi generasi yang berkulitas (SDM berkualitas), baik fisik maupun non fisiknya. (2) Menghasilkan generasi (SDM) yang berkulitas diperlukan kondisi lingkungan yang sehat, baik lingkungan fisik, sosial, ekonomi, budaya dan sebagainya, serta pe- 
rilaku yang kondusif bagi kesehatan. (c) Paradigma pelayanan kesehatan perlu diubah dari pelayanan konvensional ke pelayanan kesehatan paradigma baru, yang mengutamakan preventif dan kuratif tanpa meninggalkan pelayanan kuratif dan rehabilitatif serta dengan sasaran utama orang sehat tanpa mengabaikan orang sakit.

\section{Daftar Pustaka}

1. Ministry of Health, Republic of Indonesia, Indonesia Health Profile
2005, Jakarta 2005

2. Departemen Kesehatan R.I, Indonesia Sehat 2010: Visi Baru, Misi, Kebijakan dan Strategi Pembangunan Kesehata, Jakarta, 1999.

3. Konsorsium Ilmu Kesehatan Indonesia, Kesehatan dan Pembangunan, Jakarta, Juli 2003.

4. Biran Affandi, Millennium Development Goals: Target and Indicators, A Review, Dewan Guru Besar Uninversitas Indonesia, Kampus Depok, 2006. 